\title{
MINASY GALERÍAS. EL SISTEMA DEFENSIVO SUBTERRÁNEO DE LA PLAZA DE ORÁN
}

\author{
Souad Metair, \\ Master oficial de conservación del patrimonio arquitectónico, \\ Universitat Politècnica de València (UPV). \\ souadoran@hotmail.com

\section{Guillermo Guimaraens Igual} \\ Instituto de Restauración del Patrimonio. \\ Departamento de Composición Arquitectónica (UPV).
}

Resumen: la ciudad de Orán, enclavada en el noroeste de Argelia, es uno de los presidios más célebres de la corona española entre los siglos XVI y XVIII. la plaza cuenta con uno de los sistemas defensivos más desarrollados del norte de áfrica, con más de veinte obras fortificadas construidas por importantes ingenieros de la época. el presente artículo ofrece el resultado de la investigación documental, a partir de las fuentes halladas en los diversos archivos históricos, sobre aquellos informes y cartografía comprendida entre los siglos XVI y XVIII. la investigación deduce la organización del sistema defensivo de la plaza de Orán y se centra en el análisis de su prodigiosa red de minas y galerías subterráneas.

Palabras Clave: patrimonio, fortificación, abaluartada, Orán, Argelia, minas, galerías subterráneas

Abstract: The city of Oran, located in northwestern Algeria, is one of the most famous presidio of the Spanish crown between the XVI and XVIII centuries. The fortified city has one of the most developed defensive systems in North Africa, with more than twenty fortified works built by important engineers of that era. This article offers the result of the documentary investigation, from diverse historical archives sources, of those reports and cartography included between the XVI and XVIII centuries. The investigation deduces the organization of the defensive system of Oran and focuses on the analysis of its prodigious network of underground mines and galleries.

Keywords: heritage, fortification, bastioned, Oran, Algerie, mines, underground, galleries. 


\section{Introducción. La fortificación de Orán}

La red de defensa subterránea de la ciudad de Orán es el resultado de un proceso constructivo emprendido especialmente a raíz de la segunda ocupación española de la plaza (1732-1792). No obstante, la plaza ha experimentado un proceso evolutivo considerable desde su fundación entre 902 y 903 por los andalusíes Omeyas, y, como suele suceder en el mundo de la fortificación, en el momento en que se implementan las innovaciones de la fortificación abaluartada, se aprovechan el conjunto de virtudes tácticas que las intervenciones preexistentes ofrecen.

Es preciso resaltar que el papel táctico de Orán no puede entenderse sin la presencia de Mazalquivir. Esta última constituía un abrigo natural idóneo ante los vientos dominantes para las embarcaciones omeyas. Pero su topografía acusada dificultaba las comunicaciones y la fluidez de las relaciones comerciales con el interior. A su vez carecía de fuentes de agua. Es por ello por lo que Orán, en sus cercanías, con agua abundante, su huerta y las tribus afincadas en sus cercanías que facilitan los intercambios, se convierte en el emplazamiento idóneo para los intereses Omeyas.

La conquista de Orán impulsada por el cardenal Cisneros con las reticencias del rey Fernando, será definitivamente financiada con fondos del arzobispado de Toledo y, en ella, participarán Diego de Córdoba, como teniente general, y Pedro Navarro, como jefe general. Además de tener aspiraciones religiosas, la campaña pretende la seguridad del Mediterráneo Occidental, donde la piratería otomana no sólo incomoda el comercio, sino que alimenta un lucrativo negocio esclavista con sus correrías por las costas orientales y meridionales de la península ibérica.

El primer periodo de ocupación española se extenderá de 1509 a 1708. Diego de Córdoba asumirá la capitanía general de Orán y Mazalquivir y emprenderá el proyecto de reconstrucción y refortificación de la plaza. Para ello contará con las fortificaciones neurobalísticas islámicas, constituidas en su origen, según narraba El Idrissi, por un anillo de muro de tierra dentado con torres y una alcazaba en la orilla izquierda del Río de los molinos. Entre las preexistencias destacaba entonces la fortificación de Bordj el Ahmar, en el emplazamiento del actual Rosalcázar (1), construida bajo el mandato de Abul Hassan, príncipe merínida (Lespes, 2003, p. 64). [1]

Se puede reconocer en la primera intervención española el tránsito hacia la fortificación pirobalística. Bajo el mando de Diego de Córdoba y, más adelante, su hijo Luis de Córdoba, la muralla se restaura ampli- 


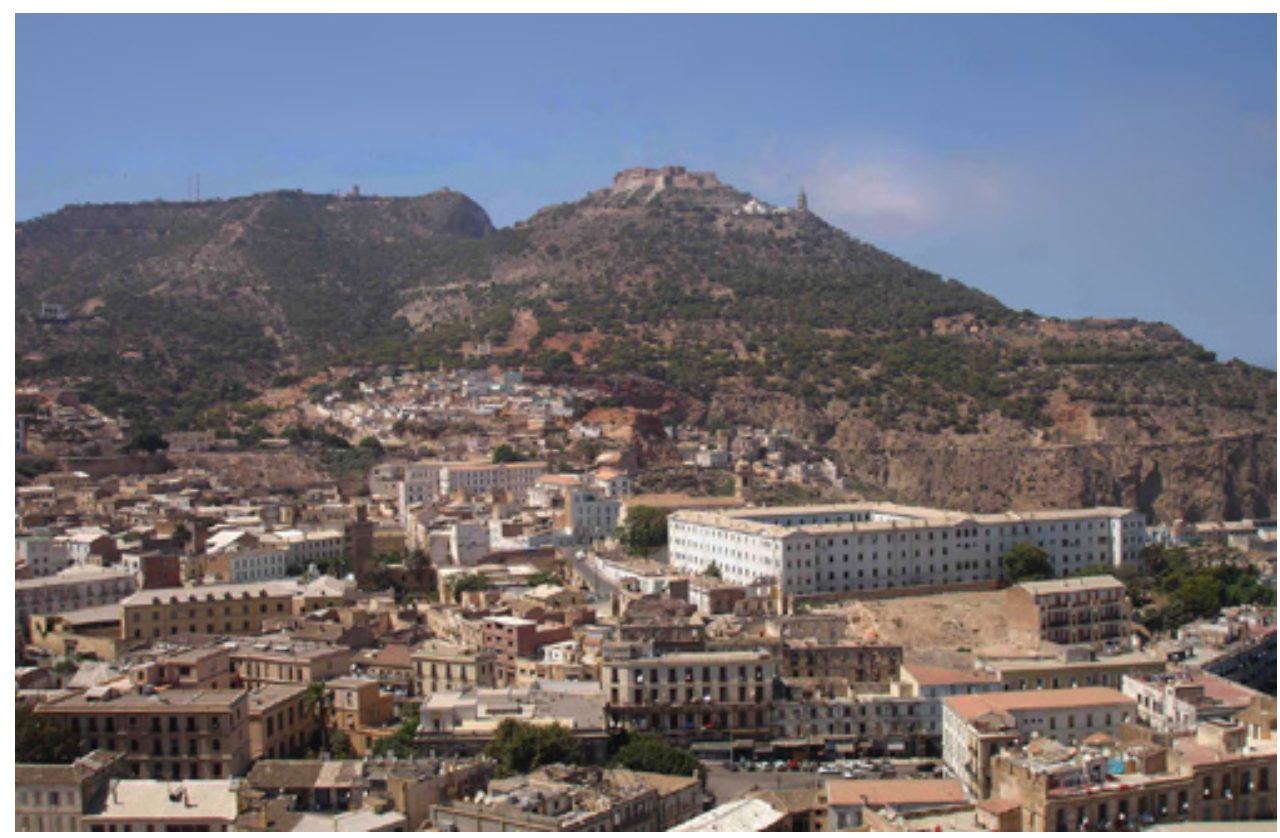

Fig.1. Vista general del casco viejo de Orán (Souad Metair, 2017).

ando su espesor con el objeto de ofrecer inercia ante el impacto artillero (Lespes, 2003, p. 66) y se cierra el cerco septentrional elevando un muro de contención de tierra. La Alcazaba (4) se adecúa y amplia como residencia del gobernador. De esta época data el proyecto del Fuerte de la Mona, destinado a proteger el puerto y vigilar su entrada. También se proyecta el Castillo de los Santos, predecesor del castillo de San Felipe (3) en la entrada sur de la ciudad, frente a la Puerta de Tremecén (14), vigilando la campaña meridional y el camino hacia el interior del continente (Fey, 2002, p. 76).

El planteamiento táctico español al que son fieles los sucesivos gobernadores españoles responde a la obviedad de una plaza aislada por todos sus frentes, tierra y mar, y destinada a resistir a toda costa a los ataques otomanos y argelinos hasta la llegada de refuerzos desde la península. Por un lado se deben defender puertos y bahías, por otro el frente de tierra por donde se concentrarán aquellos ataques que pretendan rendir la plaza.

Un hito en la fortificación de Orán lo constituye la llegada en 1564 de los hermanos Antonelli que, coordinados por Vespasiano Gonzaga, tienen la misión de mejorar y ampliar el conjunto defensivo. Ya no se trata 
aportar una solución local, sino de integrar la defensa de Orán en el plan defensivo del Mediterráneo Occidental. Entre las intervenciones acometidas se observa la línea de defensa oriental del Río de los molinos, frente a la alcazaba: el Fuerte de los Santos, apoyado en su camino por el Fuerte de San Andrés (2), y el de Rosalcázar, más al Norte, proyectado por Bautista Antonelli. Esta línea perimetral protegía Orán por el Este, y permitía otear la llegada del ejército musulmán desde Argel o desde Mostaganem (Sánchez Doncel, 1991, p.181-182).

Entre 1588 y 1589, bajo el gobierno de Pedro de Padilla, se eleva, en forma de estrella irregular, el Fuerte de San Gregorio (5), a medio camino entre La Mona y Santa Cruz (6), este último construido en 1577, dominando la bahía de Orán y el camino norte que comunica con Mazalquivir. Entre 1558 y 1708 la plaza es sometida a diversos ataques, siete de gravedad. El último, el bloqueo de 1708, pone fin a la primera ocupación española y clarifica las carencias defensivas de la fortificación del momento.

El 6 de junio de 1732, con Felipe V asentado en el trono español, se plantea un proyecto de reconquista de Orán y Mazalquivir que se materializa el 15 de junio de 1732, cuando la flota española, al mando del conde de Montemar, zarpa de Alicante con 28.000 soldados a bordo. La flota alcanzará Cabo Falcón el 30 de junio de ese mismo año, sorprendiendo a los turcos, que huyen sin plantear defensa alguna. El 1 de Julio de 1732 Orán regresaba de nuevo a manos españolas (Fey, 2002, p. 142-143).

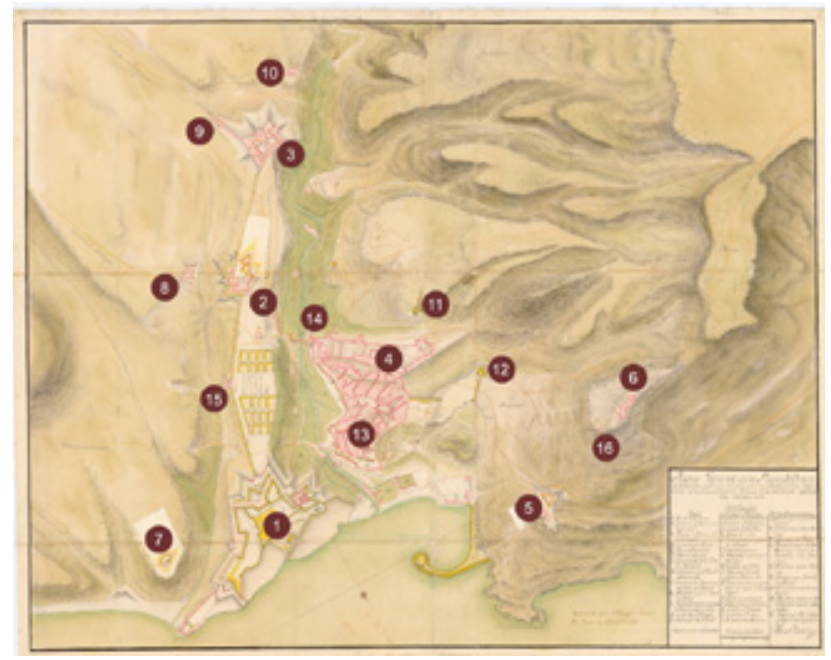

Fig.2. Plano general de la plaza de Orán de fuan Ballester y Zafra (SGM- $\left.n^{\circ} 82\right)$.
Tras aquellos años de ocupación otomana, las fortificaciones no han sufrido apenas transformaciones. El "plano general de la plaza de Orán", dibujado por el ingeniero Juan Ballester y Zafra en 1736 (Servicio General Militar (SGM), $\mathrm{n}^{\circ} 82$ ), es un buen testimonio del estado en el que se encuentran en aquellos primeros años de la segunda ocupación española así como se desvelan las intenciones defensivas. [2] 
En este momento se plantea reforzar el sistema defensivo dotando a las diferentes fortificaciones de obras avanzadas con el objeto de frenar el avance enemigo desde Argel o Mostaganem. Santa Teresa y San Miguel (7) aparecen apoyando al castillo de Rosalcázar (1); Santa Bárbara (15), en medio del camino entre Rosalcázar (1) y San Andrés (2), refuerza la cortina oriental de la ciudad, denominada la Barrera. San Luis (8) será la obra avanzada de San Andrés (2), y, finalmente, los reductos de San Carlos (9) y San Fernando (10) apoyan a San Felipe (3). De esta manera se sella la defensa oriental de la plaza. En el sector occidental, San Pedro (11) y Santiago (12) resguardan la alcazaba (4), y Santa Cruz (6) se dota de un reducto (16). A partir de este plano podemos concluir que el sistema defensivo de Orán está integrado por tres perímetros defensivos. Para conseguir que la plaza capitule, el enemigo debería acometerlos consecutivamente.

El primer perímetro está integrado por los fuertes y reductos que apoyan a los principales castillos. A raíz de la segunda ocupación española, este primer perímetro se concreta con las obras avanzadas de los diferentes reductos de traza poligonal, como Santa Teresa, San Miguel, Santa Bárbara, San Luis, San Carlos y San Fernando, formando una línea de defensa oriental, la dirección principal de los ataques, y cubriendo los flancos de los castillos respectivos. En cambio, San Pedro y Santiago se emplazan en la parte suroeste de la plaza, apoyando de este modo los bastiones y tenazas de la alcazaba y cubriendo el campo hasta San Gregorio, enclavado en el frente norte.

El segundo perímetro a sortear por el asaltante estaría constituido por los cinco castillos de relevancia que rodean la muralla principal de la ciudad y la resguardan a partir de sus enclaves estratégicos: Santa Cruz, al oeste dominando la plaza, con San Gregorio bajando la pendiente de la montaña, Rosalcázar en la parte norte frente al puerto y conectado gracias a la famosa barrera (cortina en el frente oriental) con el castillo de San Andrés, que, a su vez, estaría en comunicación con San Felipe, que cerraría la barrera y vigilaría la entrada sureste a la ciudad.

Para concluir, restaría el tercer y último perímetro, integrado por la alcazaba, el núcleo central y primitivo de la ciudad, con su correspondiente muralla, pero incluyendo también el recinto que encierra a los barrios exteriores a la alcazaba (13), con los imponentes bastiones y tenazas que articulan la muralla restaurada y ensanchada por los españoles durante la primera ocupación. Esta estructura defensiva se completa con fortines como el de La Mona, que permite proteger la bahía de Orán, junto a algunas torres que, a partir de 1732, se adjuntan a este complejo 
sistema defensivo. Henri Leon Fey (2002, p. 197-198) habla de seis torres en el camino que lleva a Tremecén, entre ellas la torre Gorda, la del Campo del Deseo y la del Nacimiento, que aparece en el grabado. La torre de Los Arcos, además de la torre Atalaya, se emplazan en el camino al fuerte de Mazalquivir.

\section{La estrategia de la defensa subterránea}

Durante la segunda ocupación española de Orán, en 1732, y bajo el impulso del gobernador de la plaza Don José Vallejo, se desarrolla una prodigiosa red de minas y galerías que convierten a Orán en un claro exponente de lo que vamos a denominar la estrategia de la guerra subterránea. A principios del siglo XVIII, estos planteamientos defensivos eran frecuentes en un modo de hacer la guerra que, desde los orígenes de la fortificación abaluartada, precisaban del movimiento de tierras una vez la fortificación había decidido esconderse en el terreno. La estandarización del asedio a través de los éxitos de Vauban y las armas francesas, y la predecible estrategia ofensiva, permitían plantear supuestos defensivos que, en función del proyecto de fortificación se ejecutaban a priori o se dejaban para ser implementadas en el momento del conflicto.

En 1743, Ignacio Sala recoge en su Tratado de la defensa de las plazas, referencia en la bibliografía española, parte de las experiencias que se estaban llevando a cabo en el territorio español, incluyendo sus experiencias en la fortificación de Cádiz. Los postulados de Vauban llegaban tarde por escrito y con cierta obsolescencia, por lo que se permite hacer correcciones en la manera de plantear la defensa a unos métodos de ataque estandarizado que se habían demostrado sumamente efectivos. Llama la atención que Sala establezca matices diferenciales cuando se trata de defender el territorio africano. Las características del enemigo, ofrecían unas posibilidades que no ofrecían los ejércitos europeos. En el tratado se puede observar el interés prioritario que se concentra en la guerra de minas. Ante el conocimiento de las pautas de asedio, se proponen estrategias para dilatar la toma. En relación con la mina Real de la plaza de Ceuta, sostenía Sala, "que el modo de sitiar las plazas de los Europeos, no da lugar a poder ejecutar estos trabajos subterráneos tan dilatados, y por eso es menester tenerlos adelantados antes de que llegue la ocasión" (Sala, 1743, p. 27). Si bien el aprovechamiento de recursos y el efecto sorpresa sugería el apoyo de obras de campaña en el momento del asedio, se tiende a prevenir y anticipar la futura defensa con obras auxiliares, donde las contraminas juegan un papel esencial.

La tratadística, y así lo recoge Sala, recomienda el uso de hornillos 
distribuidos por el glacis (Sala, 1743, p. 22). Al mismo tiempo, especialmente cuando nos encontramos con una situación de foso seco, se cuenta con el papel demoledor que juegan las minas. Un aspecto fundamental de las minas defensivas es que deben diseñarse y utilizarse para volar los alojamientos y los trabajos del sitiador, sin dañar, por ejemplo, el camino cubierto y su parapeto. El requisito que se recomienda es que la recámara de la mina se encuentre más distante del parapeto de camino cubierto que "el grueso de la tierra que se tiene encima" y que se pretende levantar con la voladura (Sala, 1743, p. 23). Por ello, la estrategia defensiva debe procurar que nunca los trabajos del sitiador lleguen a alcanzar el camino cubierto o profundicen lo suficientemente como para alcanzar las contraminas. En este caso es fundamental alentar los ataques defensivos en superficie con el hostigamiento desde la fortificación o salidas eventuales. Se entiende que el sitiador, en primera instancia, centra sus esfuerzos en el establecimiento de posiciones, asentamiento de cabezas de trinchera, alojamientos, plazas de armas y caballeros ofensivos. Es en ese momento cuando se debe recurrir al uso de los hornillos y las minas forzando al sitiador a buscar la seguridad de la guerra subterránea y, por tanto, a asumir un asedio que se desarrollará con más lentitud. Recordemos que el principio táctico de la defensa de la época es ganar tiempo, con el objeto de esperar la llegada de refuerzos, o bien que una acción exitosa de los ejércitos en otro frente de guerra pueda decantar la balanza en favor de los defensores, que la duración del asedio dificulte el sostenimiento del cerco, en muchas ocasiones, más gravoso para el ejército sitiador si se encuentra en territorio enemigo. No era el caso de Orán.

Otra red de hornillos solía emplazarse en el camino cubierto, con el objeto de volarlo una vez el enemigo coronaba el mismo y emplazaba sus baterías para arramblar con las estacadas (Sala, 1743, p. 27). No obstante, los hornillos del camino cubierto sólo debían utilizarse en última instancia, cuando los fuegos defensivos o el uso de rastrillos o traversas móviles impedía desalojar a los atacantes. Se asumía con su detonación la pérdida del camino cubierto. Aún así está línea defensiva, más allá de la contraescarpa, no estaba perdida. Aún debían resistir las plazas de armas, aisladas, pero convertidas en reductos exteriores. Estas contaban con sus propios hornillos inferiores, que serían detonados cuando el enemigo se hubiera alojado en ellas.

Tras la toma de la línea más allá del foso, el ataque ortodoxo debería acometer el asalto del revellín. La secuencia defensiva seguiría el proceso similar, detonando los hornillos correspondientes una vez asumida la pérdida de la pieza. Del mismo modo se actuaría con cualquier defensa exterior, hasta que el sitiador acometiera el ataque a la línea principal, sortean- 
do el foso para atacar el vértice saliente del baluarte o ángulo flanqueado. Este ataque suele recurrir a minas subterráneas, pero especialmente al establecimiento de baterías de brecha en las proximidades. Se trata de un momento clave de la guerra subterránea. Las baterías del sitiador se emplazarán a una distancia en torno al baluarte atacado, en relación con el revellín conquistado. Para resguardarse de los fuegos de la plaza, el sitiador construirá un espaldón. El defensor, a su vez, deberá construir una galería subterránea desde el revellín anexo, no conquistado, con el objeto de emplazar un hornillo, volar el espaldón y facilitar la vía para que los fuegos artilleros de la plaza alcancen a la artillería ofensiva (Sala, 1743, p. 35). Esta galería, sería doble, pues se desarrollaría simultáneamente desde ambos flancos contra el espaldón. Mientras todo esto sucedía, es decir, se dirimía un duelo artillero y de minas y contraminas en torno a la posición del revellín caído, se animaba a sorprender al sitiador en aquellos lugares donde pudiese considerarse a salvo. Para ello se recomendaba preparar una galería subterránea o cubierta conectando el punto medio de la cortina con la gola del revellín. Dicha galería, que podría actuar de caponera para la defensa del foso, podría servir al mismo tiempo como punto de partida de diferentes galerías. El principal objeto táctico es mantener minas sin detonar en el revellín esperando a sorprender al enemigo por la espalda, cuando emprendiese el ataque al cuerpo principal de la plaza. La detonación del revellín con los hornillos retardados destruiría sus alojamientos y generaría el desconcierto, permitiendo al defensor, quizás, recuperar la posición. Una vez el defensor queda confinado en el recinto interior, abrumado por la superioridad del atacante y con éste pudiendo ejecutar sus minas ofensivas sin dificultad, siempre quedaba el recurso de la contramina. La toma del baluarte será más o menos dificultosa en la medida que éste cuente con falsa braga, cortadura o estacadas.

No obstante, abierta la brecha, con la guarnición fatigada, la plaza estaría dispuesta para la rendición, a no ser, sostiene Ignacio Sala, que el gobernador decidiese acometer un último esfuerzo en el que podían jugar un papel importante galerías no descubiertas por el enemigo y hornillos no utilizados, tácticamente sostenidos hasta el último momento para jugar un efecto desalentador en un ejército atacante que también podía dar muestras de fatiga.

De este modo, el papel que juega el conjunto de minas y hornillos, es determinante en la guerra de sitio del siglo XVIII, y cumple misiones de diversa índole y en diferentes etapas del asedio. Muy activas en el proceso inicial, hasta el punto de contener al enemigo, y con un papel de carácter psicológico en las fases finales. En primera instancia, repeliendo 
un ataque; en última instancia, forzando una capitulación honrosa (Sala, 1743, p. 42). Si la defensa se conducía como corresponde, la perdida de la plaza implicaba, a su vez, la rendición de una fortificación completamente arruinada e inútil para el enemigo. [3]

Podríamos distinguir entre los elementos clave de la defensa el conjunto integrado por:

-Lenguas de sierpe, así denominadas por su aspecto formal, y que se plantean como zanjas descubiertas que avanzan hacia la campaña y ofrecen el primer frente de la defensa excavada, con posibilidad de ser desarrolladas en la dirección oportuna conforme las trincheras enemigas inician su avance.

-Minas y hornillos debajo del glacis. Resulta ilustrativa la propuesta de Sala indicando el modo de disponer estos hornillos mediante una

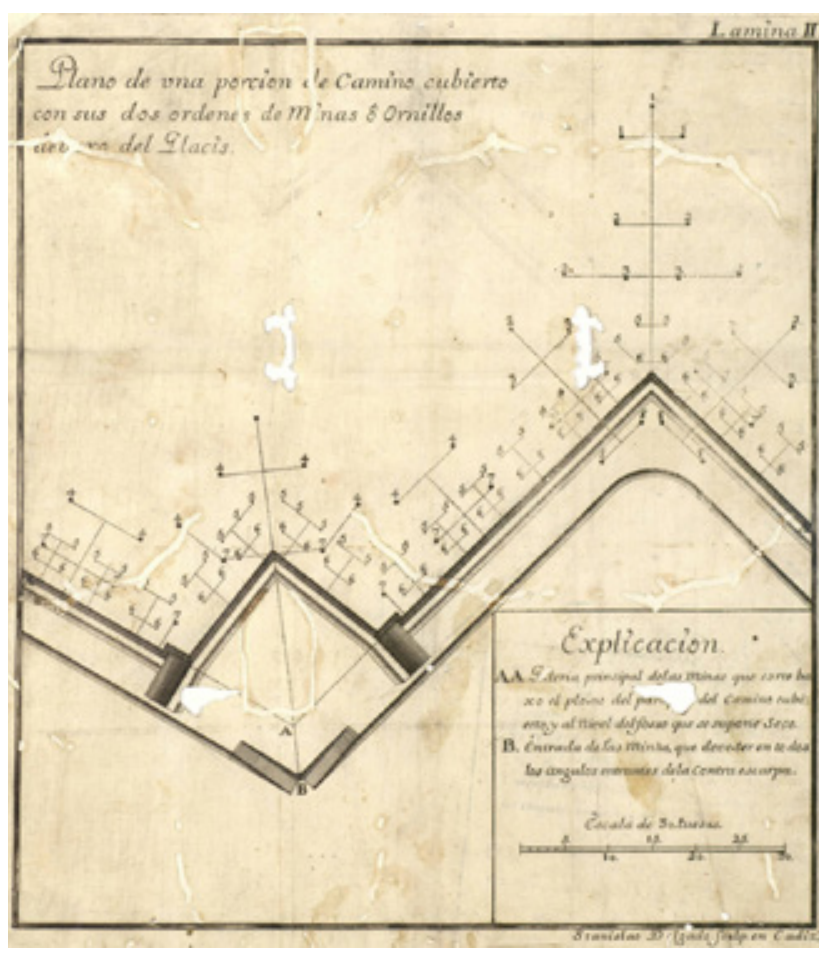

Fig.3. Hornillos en el camino cubierto de la plaza de Cádiz (Sala, 1743. Lámina II) galería paralela a la contraescarpa, justo por debajo del camino cubierto, cuyo suelo transita más o menos a la altura del lecho del foso y que alimenta diferentes niveles de hornillos, unos destinados a volar la cabeza de los ataques dirigidos a los ángulos salientes de las plazas de armas, otros destinados a volar posibles emplazamientos de caballeros de trinchera, y otros dispuestos para volar alojamientos de los atacantes. También se distinguen hornillos a un nivel más superficial destinados a impedir los trabajos del sitiador (Sala, 1743, p. 57). Otro orden de hornillos desaloja al sitiador de la cresta del glacis, y, el último grupo de hornillos, al nivel de foso, que no debería utilizarse hasta que el enemigo haya construido sus baterías y se apreste a abrir la brecha en el cuerpo principal. 
Las referencias que utiliza Sala, como ya hemos indicado, son las de Vauban, implementadas con su propia experiencia, donde hace numerosas referencias a sus propuestas en la plaza de Cádiz. En el caso de las minas, se menciona la ineludible autoridad de Dazin (1731).

En la ejecución de las galerías es determinante que se mantengan operativas bien como punto de escucha del avance de los trabajos de minado de los sitiadores, bien como emplazamiento para la construcción de nuevos ramales y hornillos según se dé el caso. La red de galerías defensivas preconcebidas era un claro ejemplo de defensa provisional, cuya principal virtud recaía en su flexibilidad para dar respuesta a las circunstancias azarosas de un asedio.

Una de las galerías de contramina más recomendadas es la que se ejecuta paralela a la línea de la muralla y por su cara exterior. Ésta evita debilitar el cimiento del recinto al tiempo que proporciona un elemento defensivo que podría ser volado en cualquier momento del asedio. Si es antes, dificultaría el acceso a los pies del recinto sin dañarlo; si es durante, afectaría a todos los atacantes en sus trabajos de aproximación; si es a posteri, es decir, cuando los enemigos han avanzado en la brecha, la voladura aislaría a aquellos atacantes que han avanzado más allá de la posición de la galería. Esta contramina paralela y por delante de la línea fortificada era una de las que más encarecidamente se recomendaba tener construida por su eficacia y la dificultad de ejecutarla en pleno duelo artillero.

Llama la atención que el conjunto defensivo subterráneo de Orán responda bastante fielmente a las teorías que, al poco tiempo de su construcción, serán recogidas por Sala en un tratado referencia de muchos ingenieros y, especialmente, en la formación Académica. Orán nos ofrece claramente una red orbital subterránea donde se distingue la red de comunicación entre posiciones defensivas en superficie, y la subred destinada a la guerra de minas concentrada en los frentes de tierra de cada una de las fortificaciones, que se observa a la perfección en el plano de la plaza que manifiesta las minas de comunicación y defensa de sus castillos y fuertes avanzados (SGM- $\left.{ }^{\circ} 85\right)$. [4]

\section{3.- las minas y galerías subterráneas de Orán}

Cuando Vallejo llega a Orán, impulsa un ambicioso plan general de fortificación en el que, como indicábamos, destaca la propuesta de defensa subterránea. Vallejo dedica todos sus esfuerzos a llevar adelante el plan, sin embargo se lamenta de la dificultad para recibir los recursos 


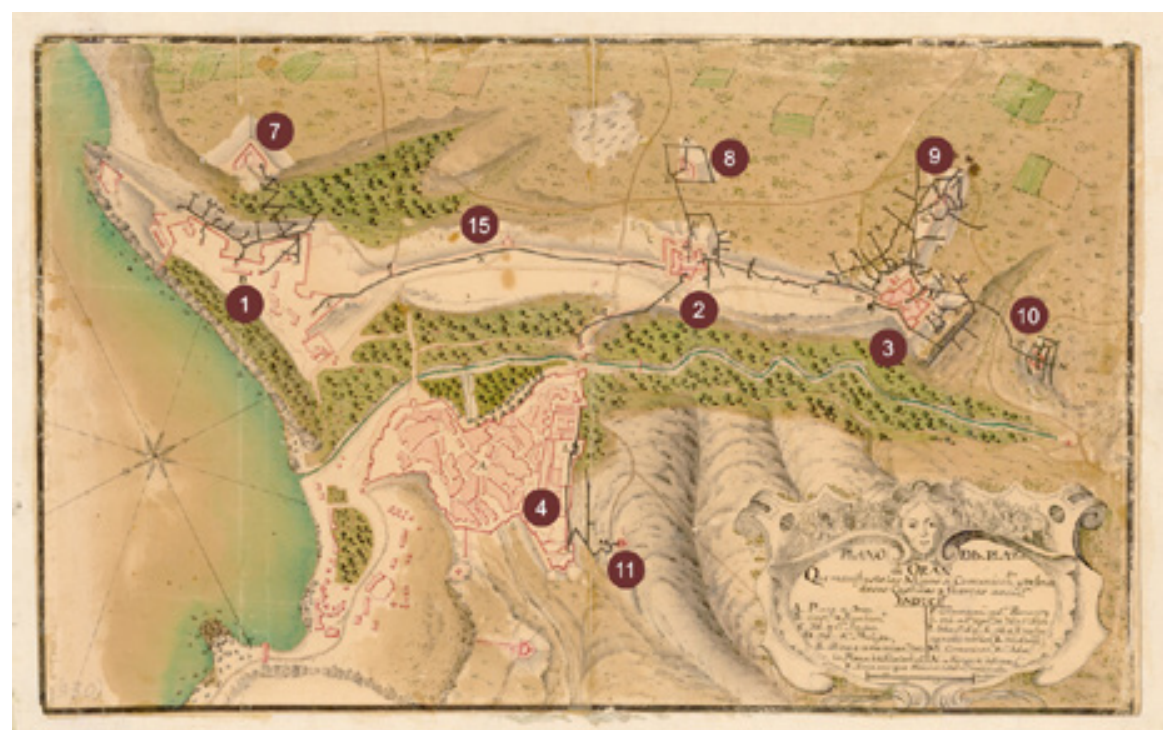

Fig.4. Plano de la plaza de Orán que manifiesta las minas de comunicación y defensa de sus castillos $y$ fuertes avanzados (SGM- $\left.n^{\circ} 85\right)$.

desde la península. No obstante y a pesar de las dificultades, será el principal responsable del aspecto defensivo que aún conserva la ciudad en la actualidad. Su compromiso, será secundado por su sucesor en el cargo, Don José de Aramburu, entre 1738 y 1742.

Las principales comunicaciones subterráneas fueron realizadas entre 1732 y 1734 por una compañía de minadores creada en la plaza, las obras se hicieron bajo la dirección del brigadier y teniente principal don Miguel de Tortosa, durante el mandato de don José Vallejo. En cuanto a los materiales y la mano de obra se pagó del Fondo de Reales de Obras (Sánchez Doncel, 1991, p.420). Vallejo pretende crear conexiones entre la plaza de Orán, sus castillos y todas las obras avanzadas a fin de facilitar la defensa y el socorro, al tiempo que complementa una red de contraminas alrededor de los baluartes y revellines susceptibles de ser atacados y minados.

\section{1.- Las galerías de comunicación subterráneas}

En el "plano que manifiesta las minas de comunicaciones y defensa de sus castillos y fuertes avanzados" de autor desconocido (fig. 4) podemos constatar que la red de minas de comunicación más importante de la plaza de Orán transcurre paralela a la barrera oriental 
de la plaza, enfrentándose estratégicamente a los ataques desde Argel o Mostaganem.

Esta galería subterránea, la de mayor longitud excavada en la ciudad, comunicaba el foso de San Felipe con el castillo de San Andrés, planteando un acceso por detrás de su revellín. Siguiendo la línea de la barrera, desembocaba en las bóvedas de los granaderos de Rosalcázar en el norte de la ciudad. La galería fue temporalmente cerrada en el tramo entre San Andrés y Rosalcázar al arruinarse partes de su itinerario. Desde San Andrés esta galería estaba conectada con la caponera de San José, que existe actualmente y cuya fecha de construcción se remonta a 1739, como testifica el escudo de su puerta.

Cada uno de los castillos, además, se relacionaba con su respectiva obra avanzada gracias a una galería subterránea. En el caso del castillo de Rosalcázar, por ejemplo, la galería arranca en la rampa del baluarte de la Encarnación y conecta con el cuerpo de guardia de San Miguel, según se indica en el plano de 1770, esta galería permitía el paso de cuatro hombres de frente (Sánchez Doncel, 1991, p.421). Estaba construida con bóveda de mampostería para evitar el desprendimiento del terreno. En su informe de 1772 el gobernador de la plaza confirma la existencia de estas galerías y añade que Rosalcázar se relaciona con la plaza, al suroeste, con el fuerte de San Miguel, al noreste, y con el castillo de San Andrés, al sureste (Hontabat, 1924, p. 241).

Siguiendo la galería principal a la cual accedemos desde el foso de Rosalcázar y paralelamente a la barrera en dirección sur, nos encontramos, a medio camino, el castillo de San Andrés, que se comunicaba mediante otra galería subterránea a su respectiva obra avanzada, el fuerte de San Luis. Otra vez en la galería principal, y desde San Andrés, el camino concluye en el castillo de San Felipe. Éste, a su vez, se comunica con sus respectivas obras avanzadas: San Carlos, al este, y San Fernando, 300 varas al sureste, con una capacidad de 70 hombres en su camino cubierto.

La inmensa red de galerías, horada todo el subsuelo de la ciudad de Orán, un ingente trabajo subterráneo continuado por sucesivas generaciones tras la iniciativa de José Vallejo, y que recibe su impulso definitivo en 1775 bajo el mando del gobernador Pedro Martín Zermeño (De Epalza y Vilar, 1988, p.103).

Una vez excavada la parte más expuesta de la ciudad, uniendo las tres obras clave de la defensa, el castillo de Rosalcázar, San Andrés y San Felipe, se planteó el frente septentrional, también trascendente en la defensa, que afecta a los dos castillos restantes: San Gregorio y Santa 
Cruz, en la línea que domina Rosalcázar. Una nueva galería principal comunicaba el fuerte de Santiago, situado al norte de la alcazaba y la plaza, con el castillo de San Gregorio y, a su vez, con el reducto de Santa Cruz, facilitando de esta manera la comunicación entre los tres puntos sin exponerse al enemigo.

Es conveniente resaltar la información contenida en el "Plano que manifiesta la Mina de Comunicación desde la Plaza de Orán al fuerte de Santiago, castillo San Gregorio, y Santa Cruz", de 6 de noviembre de 1775, dibujado por el ingeniero don Arnaldo Hontabat, que trabaja en Orán y Mazalquivir desde 1770 hasta 1775 bajo el mando de Pedro Martín Zermeño. El plano nos informa sobre la mina que comunica el fuerte de Santiago con la plaza de Orán, indicando que ésta tiene un ancho de 4 pies y 8 pulgadas (unidades del marco de Burgos), un alto de 7 pies y una longitud de 497 varas. La galería de comunicación que unía el fuerte de Santiago con el castillo de San Gregorio tenía una capacidad similar, con idéntica sección y longitud de 749 varas. El tramo de mina desde la plaza de Orán hasta San Gregorio que pasaba por Santiago fue excavado entre el 2 de enero de 1775 y el 15 de octubre del mismo año, ocupando a 400 hombres. [5]

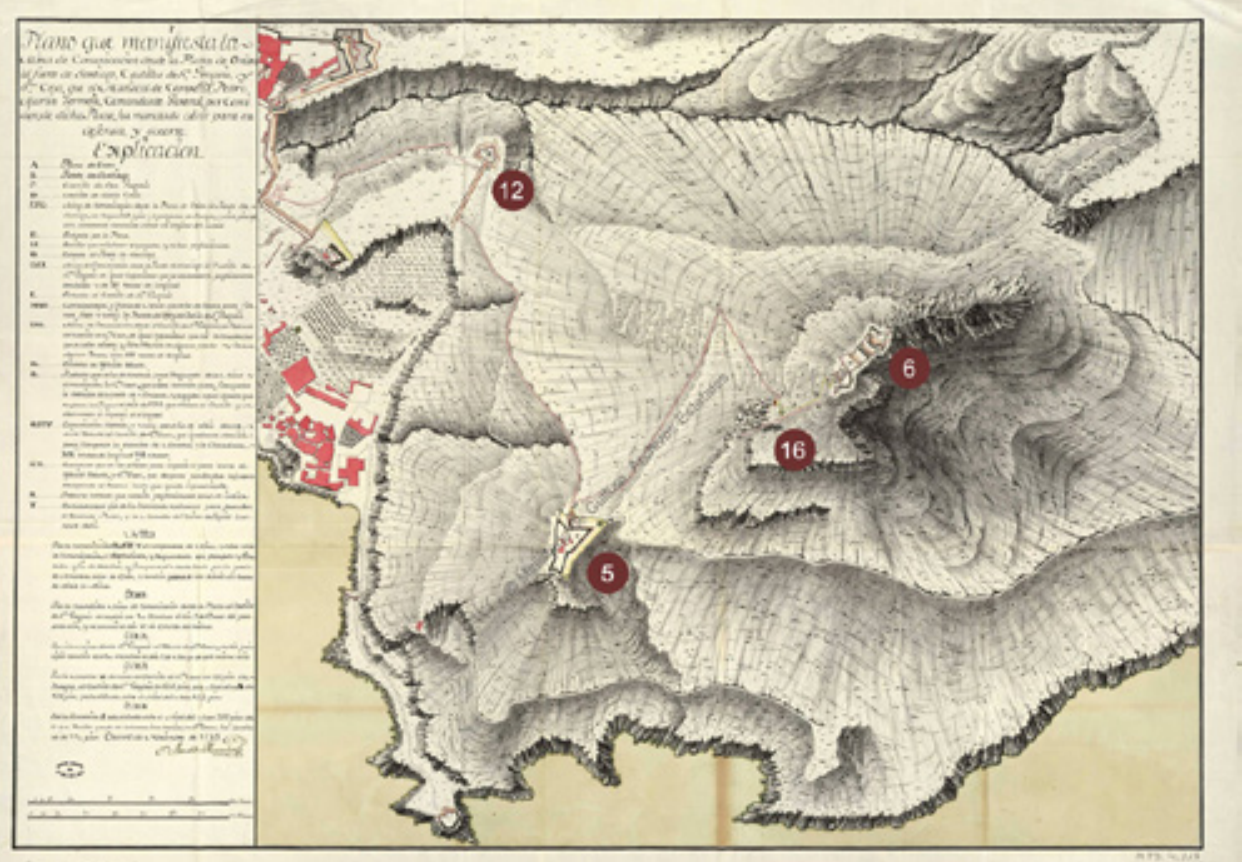

Fig.5 Plano que manifiesta la mina de comunicación desde la plaza de Orán al fuerte de Santiago, castillo de San Gregorio, y Santa Cruz (Archivo general de Simancas (AGS) AGS-MPD, 04, 117). 
La galería que comunica San Gregorio con el reducto del castillo de Santa Cruz mantenía la sección del tramo precedente con la misma anchura que el tramo anterior y con una longitud de 686 varas. Este último tramo se empezó a excavar el 8 de mayo de 1775 y trabajaron en él 400 hombres. En noviembre de ese mismo año aún está pendiente la ejecución de parte de los revestimientos. También falta adecuar un cuarto tramo que comunicaría, con una galería subterránea, el reducto con el Castillo de Santa Cruz, con una longitud de 154 varas, debiéndose adecuar sus crestas con parapetos para poder flanquear la avenida del Almarza, por el lado norte, y el monte, por el lado sur.

La tercera galería de comunicación tenía su entrada por el baluarte del Rosario en la parte Este de la alcazaba y pasaba debajo de su cortina sur hasta llegar a la entrada de la bocamina desde el baluarte de Santiago, para finalmente desembocar en el fuerte de San Pedro, obra avanzada de la tenaza suroeste de la alcazaba.

Desde el baluarte de Santiago hasta San Pedro la comunicación subterránea no permitía el paso de más de un hombre armado (Sánchez Doncel, 1991, p.420). Esta comunicación subterránea se conecta con una mina que emerge a mitad de camino entre el torreón suroeste de la alcazaba y el fuerte de San Pedro, y se traza en paralelo a la cortina sur de la alcazaba por su parte exterior como señala Ignacio Salas en su tratado.

Contrariamente a la idea generalizada que estipula que el tambor o la caponera de San José es la entrada de todas las galerías subterráneas, realmente, y desde un punto de vista estratégico-militar, no se puede permitir al enemigo el acceso a todas las galerías subterráneas que conectan todos los castillos y fuertes del sistema defensivo de la plaza desde el mismo punto, pues en el caso de que este cayese en manos del enemigo, podría minar toda la ciudad o, al menos, sus obras más importantes a través de las galerías subterráneas, a resguardo del fuego defensivo. Por ello y basándonos en la documentación analizada de los diferentes archivos consultados, se puede confirmar que desde la caponera de San José sólo se puede acceder a través de una comunicación subterránea al Castillo de San Andrés, por medio de una galería "capaz de marchar cuatro hombres de frente y acémilas cargadas" (Sánchez Doncel, 1991, p.420). [6]

\section{2.- Las minas defensivas, ramales y hornillos}

Para contrarrestar las posibles zapas ofensivas de los turco-argelinos en la plaza de Orán, los españoles desarrollan un sistema de contraminas y 


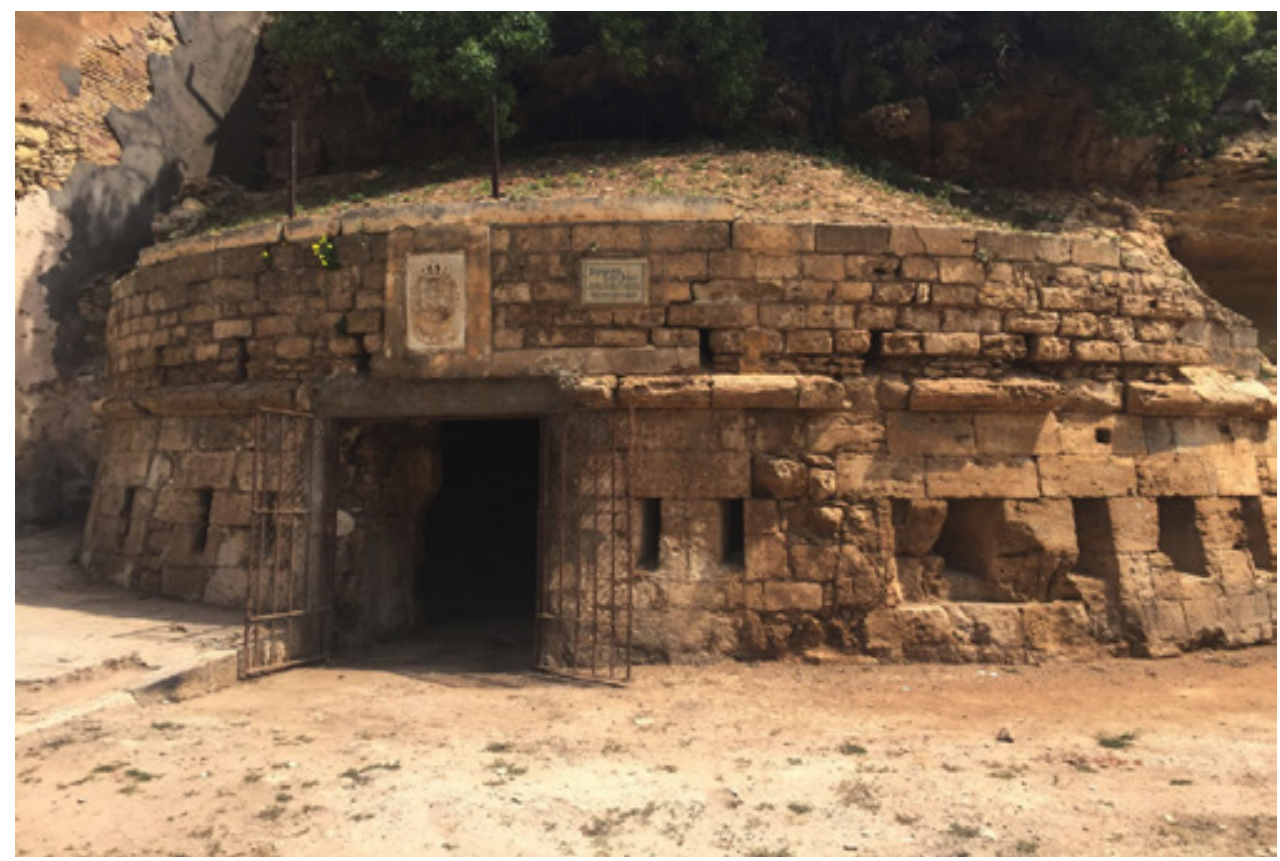

Fig. 6 Caponera de San fosé (Souad Metair, 2017).

ramificaciones en forma de peine disponiendo en sus extremidades hornos de minas. Se disponían estratégicamente alrededor de los baluartes principales de cada castillo o fuerte hasta alcanzar las espaldas de las posibles posiciones enemigas con el objeto de volarlas de acuerdo con las prescripciones recogidas anteriormente.

La primera mina defensiva de la cual tenemos constancia es la de Santa Cruz, estratégicamente excavada en su parte suroeste, orientada hacia la meseta o frente más expuesto al minado turco. El minado ofensivo se había practicado con éxito en dos ocasiones: 1708 y 1732. En la primera fecha, el éxito del ataque fue tal que condujo a la capitulación de la plaza. La mina defensiva que citamos fue excavada en la época del gobernador Vallejo, como es mencionada en su informe de 1734 (Vallejo, 1925, p. 343) En la cercana plaza de Mazalquivir no fue necesario excavar en la roca ninguna contramina, pues no se temía ataque por tierra: el frente de ataque era marítimo.

Alrededor de San Felipe hay una red de túneles tupida y compleja con varios ramales que no concluyen en ninguna salida, dado que se ejecutaron para alcanzar emplazamientos enemigos con el objeto de recurrir a la voladura. Se destacan las galerías anteriormente citadas que conectan 
el castillo con el de San Andrés o el de San Carlos y San Fernando. Esta red era tan compleja que los propios españoles la denominaron "el laberinto" (Sánchez Doncel, 1991, p.420).

De las minas defensivas hemos podido consultar varios archivos y dibujos, destacando los confeccionados en 1775 por los ingenieros Carlos Masdeu mariscal del campo y Antonio Trancoso de Castro: minas para las obras avanzadas de San Fernando, San Luis y San Carlos. Se identifican las minas recientemente excavadas y las antiguas preexistentes. Se hace hincapié en galerías, ramales y hornillos con fogatas dobles, triples y cuádruples hechas de piedra. En San Miguel nos consta que hasta el 29 de octubre de 1775 no había ni galería, ni ramal ni hornillo para su defensa y tuvieron que ser excavados ese mismo año. [7]

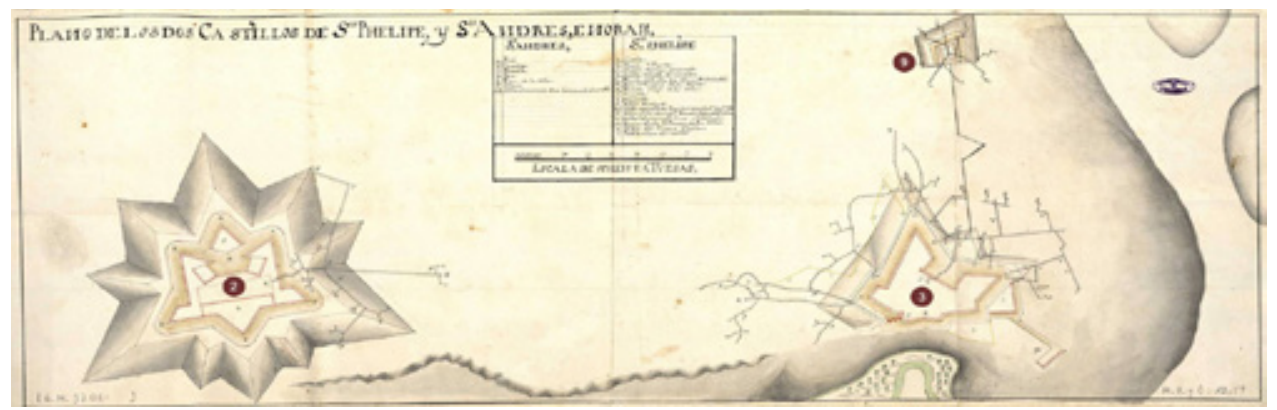

Fig. 7 Plano de los dos castillos de San Phelipe y San Andrés, en Orán (AGS- MPD, 12, 059).

Algunas de las galerías que existen en el subsuelo de Orán son el resultado de los ataque turco-argelinos al presidio español. Tenemos constancia histórica de dos de ellas, una que, según Henri Leon Fey (2002, p.199), se ha descubierto en la montaña del Murdjadjo en la meseta frente a la parte sur de Santa Cruz, construida de manera horizontal y llegando a un pozo se desarrolla en pendiente descendente para sortear el nivel de la cortadura que separa Santa Cruz de la Meseta. Una vez sorteada subterráneamente la cortadura, asciende a fin de alcanzar el nivel de la cortina sur del castillo, con el objeto de acometer su minado a resguardo del fuego defensivo español.

En el plano de 1770 tenemos constancia de una galería descrita como galería moruna inutilizada. Esta galería se encuentra frente al hornabeque más expuesto del castillo San Felipe. Su trazado se inicia en la campaña y termina en la escarpa del baluarte sureste del castillo, expresando de manera gráfica la táctica de asedio al castillo que usaban los turco-argelinos. 
Tamaña planificación defensiva para la guerra subterránea no pudo ponerse en acción. En la noche del 8 al 9 de octubre de 1790 un terrible terremoto sacudió la provincia de Orán, causando dos mil muertos en el presidio español. La ciudad fue sitiada justo después por El Dey de Argel, que presionó a la Corona Española para firmar un tratado de paz y acordar el abandono de la ciudad. Viendo en qué estado había quedado la ciudad, los españoles optaron por ceder y el Conde de Floridablanca, ministro de Carlos IV, decidió el abandono de Orán en Febrero de 1792, tras la firma del tratado, el 12 de Septiembre de 1791. En una de sus cláusulas se estableció destruir todas las fortificaciones y sus galerías subterráneas y dejar Orán en el estado anterior a 1732. Afortunadamente, la destrucción fue parcial y afectó tan sólo a una parte de las fortificaciones y de las galerías. Se trataba de impedir que este magnífico complejo defensivo cayera en manos de los argelinos o en manos de cualquier potencia europea rival, tal y como sucedió cuando en 1831 los franceses tomaron la ciudad.

\section{Conclusiones}

- El sistema defensivo español de Orán constituye la representación idónea de la evolución de los postulados de la fortificación abaluartada moderna, por una parte debido a las características del trazado de cada una de sus fortificaciones y, por otra, debido al planteamiento estratégico y el modo de conectar obras principales y obras avanzadas. Destaca el desarrollo de su red defensiva subterránea y su cierta coincidencia con las tácticas defensivas que preceptúan algunos tratados de la época, como el de Ignacio Sala. Se trata de intensificar los obstáculos al asaltante y ganar tiempo para el socorro. En el caso de Orán, con la particularidad de que éste depende principalmente de la ayuda desde la península.

-Analizando los archivos relativos a las galerías y minas subterráneas del sistema defensivo se han podido trazar todas las conexiones entre las diferentes obras que constituyen este sistema defensivo completo, detectando cada una de las entradas y salidas y su localización en los castillos y fuertes, teniendo de esta manera una idea clara sobre sus trazados, lo que nos permitirá más adelante su localización in-situ. Se puede establecer la distinción entre las minas de comunicación y de defensa excavadas por los españoles y las minas de asedio excavadas por los turco-argelinos.

-Finalmente, se ha podido confirmar que la caponera de San José no es la entrada de todas las minas de la plaza, idea generalizada en varias fuentes, más bien se trataría de la entrada a una de ellas, concretamente la galería que une la caponera con el castillo de San Andrés. 


\section{Bibliografía}

DAZIN, M. (1731), Nouveau sistême sur le manière de defendre les places par le moyen des contremines, ouvrage posthume de Mr. Dazi, Paris: Chez Jacques Clouzier.

DE EPALZA, Mickel. VILAR, Juan Baustista (1988), Planos y mapas hispánicos de Argelia siglos XVI-XVIII. Plans et cartes hispaniques de l'Algérie XVI-XVIII siècles, Madrid : Instituto Hispano-Árabe de Cultura.

FEY, Henri- León (2002), Orán avant, pendant et après l'occupation espagnole, Orán: Dar Gharb.

HONTABAT, Arnaldo (1924), "Relación general de la consistencia de las plazas de orán y Mazalquivir", en BSGAO, Tome XLIV.

LESPES, René (2003), Études de géographie et d'histoire urbaine, Orán: Ed. Bel Horizon.

LUCUZE, Pedro (1772), Principios de Fortificación, Barcelona: Thomas Piferrer. Impresor del Rey.

SALA, Ignacio (1743), Tratado de la defensa de las plazas que escrivio Mr. de Vauban, mariscal de Francia, Cádiz: Pedro Gómez de Requena.

SÁNCHEZ DONCEL, Gregorio (1991), Presencia de España en Orán (1509-1792), Toledo: I. T. San Ildefonso.

VALLEJO, José (1925), "Mémoire sur l'état des places d'Oran et de Mers-el-Kébir", en CAZENAVE, Jean (1925), Contribution à l'histoire du Vieil Oran, Revue Africaine, volume n66. 